\title{
Analisando Programas Socioeducativos em Sergipe: o caso do PETI e sua relação com a escola
}

Carlos Alberto Vasconcelos ${ }^{1}$

\section{Resumo}

0 artigo analisa o Programa de Erradicação do Trabalho Infantil (PETI) em Sergipe, buscando correlacionar o trabalho infantil na atividade agrícola com a escola. Também discute a significação do trabalho e da escola, as expectativas de crianças e adolescentes em relação ao futuro, explicando os nexos que envolvem os programas de transferência de renda para manutenção das famílias de baixo poder aquisitivo. Resultante de vasto trabalho de campo demonstra entre outros aspectos, a continuidade de crianças e adolescentes no mundo do trabalho, diante das precárias condições de vida, de produção e de renda insuficiente das famílias, bem como o funcionamento paliativo dos programas sociais de governo.

Palavras-chave: Crianças e Adolescentes; Trabalho Infantil; Programas Sociais; Escola.

\section{Analyzing Socio-educational Programs in Sergipe: the case o PETI}

\section{Abstract}

The article analyzes the Eradication Program of Child Labor (PETI - Programa de Erradicação do Trabalho Infantil) in Sergipe, trying to correlate child labor in agricultural activitywith the school. It also discusses the significance of the work and school, expectations of children and adolescents in relation to the future, explaining the nexus that involves the cash trans-

${ }^{1}$ Doutor em Geografia. Professor do Depto. de Educação, Campus Prof. Alberto Carvalho, Universidade Federal de Sergipe. Email: geopedagogia@yahoo.com.br 
fer programs to keep families with low income. Resulting from extensive fieldwork it demonstrates among other aspects, the continuity of children and adolescents in the workplace, given the precarious living conditions, production and low income of the families, as well as the palliative functioning of social programs of government.

Keywords: Children and Adolescents, Child Labor, Social Programs; School.

\section{Introdução}

O panorama socioeconômico do Brasil ainda se caracteriza historicamente como concentrador de renda e, sobretudo, excludente, agravando, portanto, a pobreza absoluta produzindo uma enorme reserva de força de trabalho, levando milhões de famílias a viverem em situação de extrema miséria, sendo submetidas a rendimentos iguais ou inferiores a um salário mínimo. Nessa ótica, emerge o trabalho realizado por crianças e adolescentes que tem sido objeto de diversas pesquisas, comprovando impactos negativos na vida adulta dessas crianças e, até certo ponto, no desenvolvimento econômico e social do país. Esta assertiva é discutida ao longo deste texto, revelando a utilização e a forma de exploração do trabalho infantil no Brasil, em especial em Sergipe, ao longo dos anos e seus reflexos na educação. É um texto oriundo da tese do autor, relacionada à temática, desenvolvida no estado de Sergipe, com vasta pesquisa de campo, empreendida no período de 2007 a 2009.

0 trabalho infantil no Brasil está, em grande maioria, associado a formas tradicionais de agricultura familiar, especialmente nas áreas de menor desenvolvimento das forças produtivas. As melhores oportunidades de trabalho no Brasil urbano-metropolitano as quais se concentram nas regiões sul e sudeste, mas que não prescindem do complemento do trabalho infantil e estimulam crianças e adolescentes a abandonarem a escola. 
A despeito de haver na literatura disponível certa concordância de que a pobreza seja a principal causa do trabalho infantil, estudos recentes questionam a força dessa correlação. Considera-se uma conclusão simplista de política social, pois não seria suficiente acabar com a pobreza para erradicar o trabalho infantil. Ademais, como eliminar a pobreza requer investimentos sociais que demandam tempo para surtir efeito, o problema do trabalho infantil só seria equacionado a longo prazo, quando o processo de desenvolvimento beneficiasse todos os segmentos da sociedade. Esse argumento respalda-se em estudos de Barros e Mendonça (1996) que indicam alta participação de crianças brasileiras entre 10 e 14 anos na força de trabalho, comparativamente a outros países. Esse fato não é explicado apenas pela pobreza ou pela maior desigualdade, mas sim pelo modo do capitalismo. Segundo a OIT, no Brasil, o percentual de crianças de 10 a 14 anos que trabalham é superior ao apresentado por outros países, a exemplo da Índia $(14,4 \%)$ e da China (11,5\%). De fato, em 1990, a taxa de participação de menores de 10 a 14 anos foi quase quatro pontos percentuais mais alta do que a média dos 14 países da América Latina e mais de seis pontos percentuais maior do que a de países com renda per capita similar.

Neste contexto, é mister considerar que trabalho e educação são atividades que, a curto prazo, são competitivas e influenciam no desenvolvimento das nações. As crianças, de forma geral, deveriam estar na escola e não no trabalho. Associa-se trabalho precoce com a evasão escolar. Então, não podemos negar que há uma convergência da literatura referente a essa questão: a criança que trabalha reduz o rendimento escolar ao mínimo, comprometendo a escolaridade final, atingindo nível mais baixo do que o alcançado por aquelas que não trabalham, bem como, terão quando adultas, salários menores do que o dos indivíduos que começaram a trabalhar na idade adequada, mesmo aquelas com treinamento. Esse mecanismo é o que também se conhece como ciclo da perpetuação da pobreza. 


\section{Ações/programas de erradicação do trabalho infantil: o caso do PETI}

A adoção de programas que visam à geração de renda vem se destacando como uma das maiores estratégias de enfrentamento da pobreza dentro do processo de reordenamento da proteção social.

Dentre a diversidade de Programas, tem-se o PETI (Programa de Erradicação do Trabalho Infantil criado pela Secretaria Nacional de Assistência Social, do Ministério da Previdência e Assistência Social, em Brasília, no ano de 1996. A princípio, atendeu apenas às áreas rurais, depois se estendeu às áreas urbanas.

Esse Programa foi concebido como resposta governamental às denúncias feitas sobre o trabalho infantil especificamente no campo, com peso significativo e durante as fases áureas de determinadas culturas, a exemplo da laranja. Apesar de sua vinculação federal, o programa não atinge todos os estados da federação; fragmenta-se e assiste territórios de maior repercussão do trabalho infantil denunciado pela imprensa e por organismos da sociedade civil, além do fator político-partidário. Bahia, Pernambuco, Mato Grosso e Sergipe foram contemplados na fase inicial do programa.

0 PETI tem por objetivo erradicar todas as formas de trabalho infantil do país e ao mesmo tempo propõe-se ao resgate da cidadania de seus usuários e inclusão social de suas famílias. Atende às diversas situações de trabalho de crianças e adolescentes, com idade inferior a 16 anos.

Em Sergipe, resulta da preocupação e mobilização da sociedade civil, inclusive de autoridades e entidades sindicais, com a problemática do trabalho infantil. O PETI iniciou-se em 1997, mais especificamente nos municípios citricultores, cujo foco de trabalho infantil era visível, principalmente no município de Boquim, e que depois se expandiu para os demais municípios produtores. 
Diniz (1999), Rodrigues (2002) e Santana (2006) elaboraram estudos sobre o trabalho infantil na citricultura, cujos impactos sensibilizaram os poderes governamentais e culminaram com a implementação do PETI, com inclusão de denúncias veiculadas na imprensa local, notadamente aquelas provenientes do presidente do Sindicato dos Trabalhadores na Citricultura.

Também contribuiu para a inserção do PETI em Sergipe a elaboração de um documento denominado Carta de Boquim. Assinada pelos prefeitos dos municípios envolvidos com a citricultura no território centro-sul, estes reivindicavam medidas governamentais para enfrentamento do problema. Toda essa mobilização culminou com a inclusão do PETI no estado, tendo o presidente Fernando Henrique Cardoso implantando o programa oficialmente em julho de 1997.

A proposta do PETI é incluir toda criança na escola, evitando o envolvimento dela como trabalho. À princípio, o programa concedia mensalmente bolsa de $\mathrm{R} \$ 25,00$ por criança de até 14 anos. De maneira geral, as famílias em situação de extrema pobreza têm direito a receber mensalmente o valor de $\mathrm{R} \$ 50,00$, do benefício básico, e cumulativamente o benefício variável, observando o limite de $\mathrm{R} \$ 45,00$. Nesse caso, a família poderá receber até $\mathrm{R} \$ 95,00$. Por exemplo, uma família em situação de extrema pobreza recebe $R \$ 50,00$ e mais $R \$ 15,00$ porque possui uma criança com idade inferior a 16 anos, então essa família passará a receber $\mathrm{R} \$ 65,00^{2}$ mensais do Programa Bolsa Família.

A família incluída no PETI tem o direito a receber uma bolsa mensal por cada filho que for retirado do trabalho precoce. 0 valor da bolsa depende da atividade que a criança ou adolescente realizava. Para aquelas que exerciam atividades típicas da área urbana, a bolsa mensal é no valor de $\mathrm{R} \$ 40$ por criança e para

${ }^{2}$ Anualmente há alteração nos valores, com intuito de acompanhar a política inflacionaria/salarial do país. 
as que exerciam atividades típicas da área rural recebem $\mathrm{R} \$ 25$ ao mês, para cada criança cadastrada. O Ministério de Desenvolvimento Social (MDS) considera como área urbana somente as capitais, regiões metropolitanas e municípios com mais de 250 mil habitantes.

Além da bolsa, o programa destina $\mathrm{R} \$ 20$ nas áreas rurais e $\mathrm{R} \$ 10$ nas áreas urbanas (por criança ou adolescente) à denominada Jornada Escolar Ampliada, para o desenvolvimento, em período extracurricular, de atividades de reforço escolar, alimentação, ações esportivas, artísticas e culturais.

As ações do PETI em Sergipe, a partir de 1997, ocorreram de forma gradativa. Inicialmente o programa estabeleceu como meta o atendimento a 5.000 crianças e adolescentes através do Programa Bolsa Criança Cidadã em quatorze municípios da região citrícola do estado (RODRIGUES, 2002).

Atualmente, o Programa de Erradicação do Trabalho Infantil está associado ao programa Bolsa Família. Entretanto, até julho de 2009 havia 30.470 menores cadastrados no programa no estado, segundo dados cadastrais da Coordenadoria Estadual do Programa e da Secretaria de Estado da Inclusão, Assistência e Desenvolvimento Social (SEIDES).

Como se visualiza na tabela adiante, a estatística de crianças e adolescentes cadastrados no território centro-sul de Sergipe totalizou 13.151 beneficiados, o correspondente a 43,2\%do total do estado, que é de 30.470 . 
Tabela 1: Número de crianças cadastradas no PETI. Sergipe. Municípios da citricultura, 2009.

\begin{tabular}{l|c|c}
\hline Município & Número de cadastrados & Percentuais \\
\hline Arauá & 893 & 6.8 \\
\hline Boquim & 1.808 & 13.7 \\
\hline Cristinápolis & 853 & 6.5 \\
\hline Estância & 1.074 & 8,2 \\
\hline Indiaroba & 570 & 4,3 \\
\hline Itabaianinha & 1.145 & 8,7 \\
\hline Itaporanga d' Ajuda & 661 & 5,0 \\
\hline Lagarto & 1.220 & 9,3 \\
\hline Pedrinhas & 530 & 4,0 \\
\hline Riachão do Dantas & 815 & 6,2 \\
\hline Salgado & 414 & 3,1 \\
\hline Santa Luzia do Itanhy & 423 & 3,2 \\
\hline Tomar do Geru & 1.883 & 14,3 \\
\hline Umbaúba & 862 & 6,6 \\
\hline TOTAL & 13.151 & 100,0 \\
\hline
\end{tabular}

Fonte: SEIDES, 2009

Percebe-se que no território centro-sul, com apenas 14 municípios dos 75 do estado, concentram-se $43,2 \%$ dos cadastrados do PETI, demandando maiores recursos. Isso demonstra a alta incidência de trabalho infantil. É notável que apenas dois municípios, Boquim e Tomar de Geru, representam juntos 28\% de todo o número de cadastros do território. A justificativa para essa situação, além da utilização do trabalho infantil nos laranjais, apresenta uma diferenciação: Boquim, pela tradição histórica onde foi implantado o programa no estado-, e Tomar do Geru, pela utilização da força de trabalho de menores na extração e quebra de pedras em pedreiras.

Por outro lado, alguns problemas detectados por familiares e pelas prefeituras em relação ao PETI foram constatados por Vasconcelos (2009) e Aquino (2002) questão: 1) 0 grande dilema das crianças não incluídas no programa, agora proibidas de 
trabalhar, sob a fiscalização dos Conselhos de Assistência à Criança e ao Adolescente e pelo próprio poder judiciário local, os quais responsabilizavam os pais criminalmente; 2) A exclusão das crianças que completaram 15 anos. 0 que fazer com e para elas quando perderem a bolsa? Deixarem a escola e voltarem para o trabalho? 3) A própria bolsa é geradora de algumas dificuldades, devido ao atraso em seu pagamento (as famílias passam 2 e até 3 meses sem nada receber), provocando um clima de incerteza quanto à continuidade do programa; 4) Os pais das crianças reclamam dos critérios de seleção para a bolsa os quais favorecem algumas pessoas que não se enquadram no programa, inclusive de famílias com rendas.

Entretanto, todas essas questões detectadas no programa, a partir da amplitude reduzida, da seletividade e dos critérios estabelecidos em nível nacional, das próprias dificuldades apresentadas pelas prefeituras e dos levantamentos teóricos analisados e mencionados ao longo dos estudos, percebe-se a debilidade de um programa imposto que não penetra nas causas reais do trabalho infantil; não possibilita aos pais condições de manterem estrutura das suas famílias sem dependerem do trabalho dos filhos. Como observou um representante do Sindicato dos Trabalhadores Rurais na dissertação de (DINIZ, 1999, p.59), o programa não fez acabar com o trabalho infantil; este foi desativado como toda atividade na citricultura, agora temos apenas desempregados, adultos e crianças.

Reforçando o objetivo do PETI, em parceria com os setores dos governos estaduais e municipais e da sociedade civil, que é pôr fim às atividades perigosas, insalubres, penosas ou degradantes nas zonas urbana e rural, questiona-se: até que ponto esse programa vem sendo aceito pela população? Ele tem um caráter esporádico ou contínuo? Que tipo de ações vem desenvolvendo? Como as crianças atendidas vêm concebendo o PETI? Houve afastamento das crianças do trabalho infantil e consequentemente melhor produtividade na escola? E agora, como está funcionando com a inclusão a outros programas? 
Apesar das incongruências, o setor educacional, a partir de dados das prefeituras revela que houve um aumento significativo no índice de aprovação nas escolas, com menor taxa de evasão.

\subsection{Programas socioeducativos: transferências de renda}

Vários programas de transferência de renda focalizados na pobreza foram instituídos ao longo da década de 1990. Voltados para famílias de baixa renda, geralmente os programas vinculam a transferência de renda à frequência escolar. Em 2001, o Bolsa Escola $^{3}$ era o programa federal de transferência de renda com maior número de beneficiários, quase $2 / 3$ da população-alvo (menores de 6 a 15 anos com renda familiar per capita igual ou inferior a meio salário mínimo) ou 8,3 milhões de beneficiários. A proporção de beneficiados é maior nas regiões nordeste, norte e sudeste. Esse fato de certa forma surpreende devido à exigência de frequência à escola dos programas. Na verdade, apenas confirma que trabalho e estudo concomitantes são possíveis, pois muitos menores de idade trabalham e estudam. Kassouf (2004) estima, a partir dos dados da PNAD, que os programas de transferência de renda reduzem as horas mensais trabalhadas, mas não encontram resultado conclusivo sobre a redução do trabalho. Entretanto, é perceptível a diminuição do trabalho, especificamente nas áreas rurais, consequentemente está aumentando a frequência escolar.

Chama a atenção o fato de a proporção e o número absoluto de famílias beneficiárias serem maiores na região nordeste. Isso não se deve ao caso de a região ser a mais pobre do país, pois a amostra analisada da PNAD inclui apenas famílias com renda inferior de até meio salário mínimo. As famílias beneficiárias aparecem em maior proporção na área rural. A distribuição de

${ }^{3}$ O programa Bolsa Escola Federal, além dos programas Auxílio Gás, Bolsa Alimentação e Cartão Alimentação (Fome Zero) passaram a integrar o programa Bolsa Família em 2003. 
benefícios está, na verdade, vinculada à implementação do Programa Bolsa Escola, que começou atendendo prioritariamente a municípios já assistidos anteriormente, seguidos dos 14 estados com menor IDH - Índice de Desenvolvimento Humano - e/ou pertencentes a microrregiões com IDH igual ou inferior a $0,5^{4}$.

Discorrendo sobre o Programa Bolsa Escola, anterior ao Bolsa Família, Arbache (2003) e Santana (2006) avaliam-no colocando que, apesar do programa compensatório, há indícios de saída sustentável da pobreza, pois se verifica relação explícita entre a distribuição dos recursos para as famílias e a formação do capital humano.0 programa tem por evidência a relação positiva entre a permanência da criança na escola e sua inserção no mercado de trabalho. Este programa tem por forte apelo o combate ao trabalho infantil e o abandono precoce da escola.

A transferência de renda pode ser apontada como uma medida viável para a eliminação do trabalho infantil no Brasil, através do programa Bolsa Escola, que transfere para as famílias pobres de $60 \%$ a $80 \%$ do valor médio do trabalho infantil por criança em idade escolar que esteja frequentando a escola, independentemente de a criança ser ou ter sido trabalhadora. Além do que, atualmente, todos os programas estão associados ao Bolsa Família (OIT, 2005).

Partindo da hipótese de que as crianças trabalham, entre outros motivos, para complementar a renda da família, ou seja, trabalham porque são pobres, acrescenta-se:

As iniciativas que visam ao combate ao trabalho infantil ajudam a diminuir as diferenças entre pobres e não-pobres, uma vez que atuam numa de suas causas. Enfim, são ações capazes de quebrar o ciclo que mantém pobres várias gerações de uma mesma família (FERRO, 2003, p.5). 
Hoje, o Bolsa família é transferência de renda para as famílias, que, para terem direito, precisam permanecer com os filhos na escola e manter atualizado acompanhamento da saúde.

O PBF (Programa Bolsa Família) foi criado em outubro de 2003, formalizado e regulamentado em 2004 pelo Ministério do Desenvolvimento Social e Combate à Fome (MDS), sendo parte integrante do Sistema Único de Assistência Social (SUAS). Tende articular os diversos agentes políticos em torno da promoção e inclusão social das famílias que vivem em situação de pobreza ou/e extrema pobreza.

O PBF integra o fome Zero, que visa garantir o direito à alimentação adequada, promovendo a segurança alimentar e nutricional. A unificação de outros programas ao Bolsa Família permitiu atender a maior número de indivíduos. Ressalta-se que atualmente novos programas e ações estão emergindo com intuito de subsidiar as famílias com baixa renda, entretanto, não adentraremos em detalhes, devido a minuciosa atenção e detalhamento que requer.

Estudo do MDS (2007) indica que a frequência escolar entre crianças pobres de 7 a 14 anos atendidas pelo Programa Bolsa família é 3,6\% superior em relação aos que não recebem o benefício. Na região nordeste essa diferença é ainda maior, 7,1\%. A evasão escolar é também menor no caso dos beneficiários do Bolsa Família. Nas famílias pobres, a evasão é de 1,8\% menor em relação aos lares não incluídos no programa.

Em Sergipe todos os municípios são atendidos com estimativa crescente de inclusão de famílias pobres, dentro dos limites estabelecidos pelo programa, para famílias extremamente pobres e famílias pobres. Em junho de 2009 havia 295.338 famílias cadastradas em todo o estado, sendo atendidas com o benefício 198.461.

Em relação à frequência do aluno na escola, o Programa analisa sua ausência, justificando a partir de diversos motivos, como: 
doença no aluno; óbito na família; inexistência de oferta de serviços educacionais; conclusão do ensino médio; gravidez, mendicância; negligência de país ou responsáveis; trabalho infantil; violência sexual e doméstica.

0 índice dos que não alcançam a frequência exigida oscila em torno de 2\% a 3\% apenas. Segundo a coordenadora do PBF na Educação em Sergipe, há acompanhamento das famílias, especificamente dos beneficiados que estão na escola. Caso o acompanhamento não corresponda à exigência do programa, em relação à frequência exigida, comunica-se aos pais, procede-se à suspensão temporária e, finalmente, bloqueia o benefício. Se for revertida a situação de agravo, o benefício retorna. A coordenadora destaca a importância do Programa, ressaltando que (...) pais pagam reforço escolar para seus filhos com a renda que recebem (...) o Bolsa família é o líquen do Fome Zero (Entrevista em 25 de setembro de 2009).

\section{Ensaios sobre educação e trabalho infantil}

É perceptível que o trabalho infantil contraria ou fere o direito fundamental à educação. Neste sentido, ao ratificar a Convenção 182 da Organização Internacional do trabalho (OIT), em 17 de junho de 1999, o governo brasileiro se comprometeu a tomar medidas imediatas e eficazes para assegurar a eliminação das piores formas de exploração de mão de obra infantil. Dez anos depois, no entanto, 4,8 milhões de pessoas entre 5 e 17 anos continuam trocando a infância e a adolescência por diversas formas de trabalho, incluindo o doméstico, conforme aponta a PNAD de 2007.

Segundo Vasconcelos, (2009), a partir de pesquisa de campo em Sergipe, constata-se significativa presença de crianças e adolescentes que, de forma voluntária ou remunerada, executam a fazeres domésticos. Essa situação não foge à regra geral e nacional, tendo em vista que o Brasil ocupa a terceira posição nessa modalidade de trabalho infantil (OIT, 2004). 
O exercício de afazeres domésticos por crianças e adolescentes, em função da tradição que cerca a formação da família brasileira é destinado com maior frequência e intensidade às meninas, tendo em vista, entre outros motivos, a perspectiva de que futuramente assumirão a responsabilidade de sua realização e/ou do seu gerenciamento.

No trabalho infantil, os municípios que compõem o centro-sul sergipano demonstram a redução do trabalho, embora permaneça significativo o número de crianças e adolescentes que trabalham. São 6,3 milhões de menores em 2001, distribuídos na faixa etária de 5 a 15 anos, dos quais 38,23\% estão na zona rurale $61,77 \%$ na zona urbana, em um total de 12.235 e 19.770, respectivamente, no estado de Sergipe. No nordeste, o número mais elevado concentra-se na Bahia, com $26,2 \%$ dos trabalhadores infantis (IBGE/PNAD, 2002).

Uma das consequências mais notórias do trabalho infantil é a queda no desempenho escolar. Apesar de matriculado e de sua frequência na escola, o aluno não tem educação de qualidade ou uma aprendizagem significativa. Estudos mostram que as crianças trabalhadoras sofrem desgaste físico constante o que impede seu desenvolvimento intelectual; e isso é um fator que contribui para a educação brasileira manter-se em um patamar baixo. As avaliações do MEC apontam que os municípios com maior taxa de trabalho de menores responderam por baixos índices de Desenvolvimento da Educação Básica (IDEB), diz o gerente do Programa Internacional para Erradicação do Trabalho Infantil da Organização Internacional do Trabalho (OIT), Renato Mendes, em entrevista ao UOL notícias em 18/9/2008.

Segundo o relatório Emprego, Desenvolvimento Humano e Trabalho Decente (CEPAL/PNUD/OIT), lançado em 2008, 19\% das crianças e dos adolescentes no Brasil que trabalham não estudam; e os que permanecem nas salas de aula, devido ao cansaço e ao tempo reduzido para se dedicar aos estudos, muitas vezes não alcançam aprovação. 
Em geral, o trabalho tem um efeito perverso no desenvolvimento educacional da criança e do adolescente. Esse efeito, no entanto, depende da idade, tipo e duração do trabalho, e pode afetar tanto a presença ou não da criança na escola, assim como seu aproveitamento.

Podemos citar três indicadores facilmente observáveis de desempenho escolar: o analfabetismo, a presença ou ausência à escola e a distorção idade-série. Nos últimos anos, o acesso à educação básica no Brasil tornou-se praticamente universal, e os dados de 2003 refletem este desenvolvimento. Somente 3,4\% da população entre 10 e 17 anos de idade foi identificada como analfabeta; entre os economicamente ativos neste grupo de idade, o analfabetismo se eleva para 4\%. Na população entre 5 e 17 anos, 91,7\% dos que não trabalham frequentam escolas, em contraste com somente 80,7\% dos que trabalham. Esta diferença se deve em boa parte ao fato de que os que trabalham são em geral mais velhos (CORDEIRO, 2006).

A distorção idade-série é uma característica bastante generalizada da educação brasileira, que apresenta um dos piores índices de repetência escolar em todo o mundo. Nos anos recentes, houve um esforço sistemático por parte do Ministério da Educação e de muitos governos estaduais para reduzir o atraso escolar, mantendo as crianças com seu grupo de idade e compensando pelas deficiências quando necessário, mas a noção de que a repetência escolar é um instrumento pedagógico importante ainda tem muitos adeptos. Teoricamente, crianças com 10 anos deveriam estar no $5^{\circ}$ ano do ensino fundamental, as de 11 no 6⿳⺈, e assim sucessivamente.

É visível que na maioria das vezes esses dados são interpretados em função do impacto do trabalho sobre a educação, mas é bastante provável que eles surtam também um efeito inverso, sobretudo para os grupos de menor idade, ou seja: que a ausência na escola leva ao trabalho, e não o contrário. De fato, apesar de o acesso à escola estar praticamente generalizado no Brasil de hoje, a situação da oferta educacional ainda é precária nas regi- 
ões rurais, sobretudo a partir da antiga 5 ${ }^{\mathrm{a}}$ série do ensino fundamental. Mesmo quando existem escolas para adolescentes de 14 a 17 anos, é bastante frequente, nas áreas rurais e nas periferias urbanas, o funcionamento delas de forma precária, inclusive com professores desmotivados e despreparados, transmitindo conhecimentos que fazem pouco ou nenhum sentido para a realidade dos estudantes. A ausência ou precariedade das escolas, o atraso acumulado ao longo dos anos, a desmotivação do meio e o desejo de ter alguma renda própria, reúnem-se para constituir o número de adolescentes que abandonam a escola por volta dos 14-15 anos, e a partir daí o trabalho passa a ser a alternativa de ocupação razoável, que traz benefícios monetários imediatos e evita a ociosidade. À medida que isso ocorre, é possível argumentar que não faz sentido coibir o trabalho de crianças e adolescentes sem assegurar condições efetivas de frequentar uma escola.

Por outra parte, é possível argumentar também que se, primeiro, esperamos que surjam as condições efetivas de frequência a uma boa escola para depois coibirmos o trabalho de menores, corremos o duplo risco de que as condições não se deem nunca, e que, mesmo que as escolas deixem a desejar em termos de qualidade do ensino e de infraestrutura,é importante assegurar o acesso à escola de maneira a provocar sua melhora por meio da pressão da comunidade escolar.

Dentro das explicações sobre a ausência na escola, o suplemento especial da PNAD (2001) coloca dois importantes questionamentos sobre o abandono e a falta ocasional à escola, e os resultados principais podem ser resumidos no abandono como decisão do próprio aluno, sobretudo entre os mais velhos. É comum escutarmos ditos como "não quis frequentar a escola". 0 trabalho aparece como segunda razão, com $20 \%$ das respostas entre os mais velhos. Na área rural, um forte fator para o abandono ainda é a ausência da escola próxima à residência (16\%). A falta ocasional é explicada, sobretudo, por doença (51\% das respostas) e depois, novamente, pela decisão individual do aluno 
(não quis comparecer). Problemas com a própria escola (falta de professor, greve e questões pedagógicas) são também significativos e afetam principalmente, o segmento de maioridade.

Para muitas crianças e, sobretudo, adolescentes, a escola não é vista como garantia futura; querem mesmo é uma "boa vida". Essa afirmação pode ser averiguada nas tabulações dos dados, integrantes do trabalho de Vasconcelos (2009), apesar de na pesquisa o índice de crianças e adolescentes que estudam ser elevado (porcentagem), tendo em vista o recurso estratégico de pesquisá-los nas escolas e não nas famílias.

Tabela 2: Concepções e expectativas sobre a escola e o trabalho. Sergipe. Municípios do Centro-Sul, 2007-2008.

\begin{tabular}{|c|c|c|c|c|c|c|c|c|}
\hline \multirow[b]{2}{*}{ Municípios } & \multicolumn{3}{|c|}{ Escola e trabalho } & \multicolumn{5}{|c|}{ Expectativas Futuras (1) } \\
\hline & 苛 & $\begin{array}{l}\stackrel{0}{2 \pi} \\
\mathbf{Z}\end{array}$ & 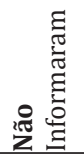 & 点 & 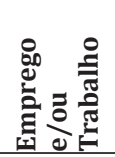 & 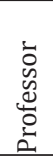 & 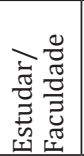 & 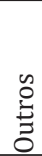 \\
\hline Arauá & 39 & 01 & - & 30 & 04 & 02 & 18 & 10 \\
\hline Boquim & 52 & 03 & - & 55 & 10 & 04 & 17 & 10 \\
\hline Cristinápolis & 38 & 01 & - & 39 & - & 15 & 02 & 22 \\
\hline Estância & 26 & - & 03 & 29 & - & 04 & - & 05 \\
\hline Indiaroba & 25 & - & - & 25 & - & 02 & - & 11 \\
\hline Itabaianinha & 50 & 01 & - & 51 & - & 11 & - & 15 \\
\hline Itaporanga D’Ajuda & 35 & 01 & - & 36 & 12 & 01 & 06 & 08 \\
\hline Lagarto & 43 & 02 & - & 45 & 06 & 06 & 08 & 21 \\
\hline Pedrinhas & 16 & 02 & - & 19 & 05 & 01 & 04 & 03 \\
\hline Riachão do Dantas & 27 & 02 & - & 29 & 10 & 02 & 08 & 08 \\
\hline Salgado & 35 & - & - & 35 & 08 & - & 18 & 04 \\
\hline Santa Luzia do Itanhy & 20 & - & - & 20 & 09 & - & 07 & 04 \\
\hline Tomar do Geru & 19 & - & - & 19 & 08 & 01 & - & 07 \\
\hline Umbaúba & 27 & 03 & - & 30 & 12 & 02 & 14 & 04 \\
\hline Total & 417 & 15 & 03 & 472 & 84 & 51 & 102 & \\
\hline
\end{tabular}

Fonte: Pesquisa de Campo, 2007/2008.

Nota: (1) As expectativas são por diversas profissões, inclusive em estudar para alcançar tais profissões, embora alguns não demonstrassem quaisquer perspectivas. 
O abandono à escola em razão da necessidade de trabalhar para ajudar na renda familiar fica evidente quando se analisa a taxa de escolarização dos adolescentes ocupados e não ocupados. De acordo com a PNAD 2007, dos adolescentes de 15 a 17 anos que trabalham apenas $21,8 \%$ estão na escola.

Ainda em relação ao trabalho e escolarização, pode-se ilustrar que os jovens em Sergipe representam em torno de $25 \%$ da população que se encontra na faixa etária de 15 a 17 anos. Também é evidente a maior presença de homens no mercado de trabalho e de mulheres nas escolas. Deve-se ressaltar que o nível de instrução de uma pessoa pode ser diferente do seu grau de escolaridade, uma vez que pode aprender fora da escola. Todavia, para se levar em conta essa diferença, ter-se-ia de organizar uma avaliação do saber das pessoas, o que foge à perspectiva dos questionamentos de nosso trabalho. Entretanto, Sergipe contou em 2006 com 70.657 alunos matriculados na $1^{\text {a }}$ série do ensino fundamental e 23.509 concluintes desse mesmo nível de ensino (MEC, 2009).

\section{Considerações Finais}

0 trabalho infantil está diretamente relacionado à história da atividade produtiva no Brasil. Além de determinantes econômicos, fatores de ordem sociocultural também influenciaram na inserção de crianças e adolescentes no mundo do trabalho.

Historicamente, o Estado vem tentando responder a essa problemática, porém é a partir da criação do ECA (Estatuto da Criança e Adolescente $)^{5}$ que são acionadas medidas mais concretas de combate ao trabalho precoce.

\footnotetext{
${ }^{5}$ O Estatuto da Criança e do Adolescente (Lei 8069/90) promoveu mudanças de conteúdo, método e gestão no panorama legal e nas políticas dos direitos da criança e do adolescente, constituindo-se em mecanismo de proteção para o qual criou sistema abrangente e capilar de defesa de direitos, inclusive no direito ao trabalho.
} 
É consenso que o trabalho infantil tem como principal origem a pobreza familiar. Diante desse fato, o governo cria uma série de programas, dando ênfase à escolarização, à geração de trabalho, emprego e renda, objetivando apoiar a família e erradicar o trabalho infanto-juvenil. Entre estes programas, podemos citar o PETI.

Como os demais estados nordestinos, em Sergipe também encontramos crianças e adolescentes envolvidos em atividades laborais, tanto na área rural como na urbana, no rural, objeto de nosso estudo, prevalece atividades agrícolas, entre elas, a citricultura.

O PETI enquanto programa que visa a erradicação do trabalho infantil não conseguiu incentivar a participação das famílias nas ações de modo a possibilitar mudanças efetivas na sua condição de vida. 0 programa tem contribuído para reforçar uma prática, de certa forma, assistencialista e clientelista, limitando-se ao recebimento de bolsa e à frequência à escola, constituindo-se em mais um elenco dos programas de combate à pobreza.

Todavia, o trabalho infantil é recurso capitalista para enfrentamento de crise. E, atualmente, reflete-se na região geoeconômica do centro sul de Sergipe, especificamente, crise semelhante à que permeia todo o país: vários trabalhadores foram dispensados, e as formas alternativas de trabalho informal não sobrevivem no campo com a mesma dinâmica produzida nos centros urbanos.

Para muitos dos pesquisados e inseridos no PETI, o trabalho é a chave de uma boa vida ou, pelos menos, de uma vida "normal". É ele que possibilita ajudar a família. É ele que exige das crianças e adolescentes estudos cada vez mais longos. 0 problema é conseguir emprego estável, bem pago e que agrade o trabalhador.

No que se refere especialmente dos municípios pesquisados, o panorama educacional em 2008 no centro-sul sergipano apresentou um total de 137.026 alunos matriculados na educação 
infantil, no ensino fundamental, no ensino médio, na educação profissional e na educação de jovens e adultos. Desse total, $63,7 \%$ estavam matriculados no ensino fundamental.

Critica-se a política de combate ao trabalho de crianças e adolescentes cujo foco único se faz pela repressão do trabalho. Defende-se a necessidade de criar condições para que o trabalho seja descontínuo. A principal destas condições é, sem dúvida, a melhoria do sistema educacional e a criação de programas eficazes de geração de emprego e renda com prioridade para as famílias específicas.

\section{Referências bibliográficas}

AQUINO, K. M. O. Trabalhadores da citricultura: Pedrinhas (1985-2001). Estância, 2002. Monografia (Licenciatura em História) Programa de Qualificação Docente, Universidade Federal de Sergipe.

ARBACHE, J. S. Pobreza e mercados no Brasil: uma análise de iniciativas de políticas públicas. Brasília: CEPAL/DFID, 2003.

BARROS, R. P\& MENDONÇA, R. S. P. Trabalho infantil e evasão escolar. Rio de Janeiro: DIPES/IPEA, 1996.

BRASIL/MDS/ASCOM. Reajuste mantém poder de compra da população de baixa renda. Disponível no site: www.mds.gov.br. Acessado em 7 de setembro de 2009.

DA SILVA, M. I. C. 0 compromisso das famílias com a erradicação do trabalho infantil: um estudo junto ao Peti em Maceió/AL. Recife, 2003. Dissertação (Mestrado em Serviço Social). Programa de Pós-Graduação em Serviço Social, Centro de Ciências Sociais Aplicadas, Universidade Federal de Pernambuco.

CEPAL/PNUD/OIT. Emprego, desenvolvimento humano e trabalho decente: a experiência recente. Brasília: CEPAL/PNUD/OIT, 2008.

CORDEIRO, R. G. 0 trabalho infantil e suas consequências sociais no brasil. Rio de Janeiro, 2006. Monografia (Especialização em Docência para o Ensino Fundamental). Instituto a Vez do Mestre, Universidade Cândido Mendes.

DINIZ, N. L. A acidez dos laranjais: o trabalho infantil na ótica das crianças e adolescentes, trabalhadores da citricultura em Boquim/SE. São Cristóvão, 1999. Dissertação (Mestrado em Ciências Sociais). Núcleo de Pós-Graduação e Pesquisa em Ciências Sociais, Universidade Federal de Sergipe. 
FERRO, R. A. Avaliação do impacto dos programas de bolsa escola no trabalho infantil. Piracicaba, 2003. Dissertação (Mestrado em Economia). Programa de Pós-Graduação em Economia, Escola Superior de Agricultura Luiz de Queiroz, Universidade de São Paulo.

IBGE/PNAD. Aspectos complementares de educação, afazeres domésticos e trabalho infantil: comentários. Rio de Janeiro: IBGE/PNAD, 2007.

.Pesquisa Nacional por Amostra de Domicílio. Trabalho Infantil, 2001 Rio de Janeiro, 2002.

Suplemento especial. Rio de Janeiro: IBGE, 2001.

KASSOUF, A. L (Coord.). 0 perfil do trabalho infantil no Brasil, por regiões e ramos de atividade. Brasília: OIT, 2004.

MEC/INEP. Resultados do censo escolar 2008: educacenso. Disponível no site: www.Inep.gov.br/censo/escolar/matricula/censoescolar_2008. Acessado em 26 de setembro de 2009.

ORGANIZAÇÃO INTERNACIONAL DO TRABALHO (OIT). 0 trabalho infantil. Disponível no site: www.oitbrasil.org.br. Acessado em 28 de dezembro de 2005 e 29 de fevereiro de 2007.

RODRIGUES, P. S. Da laranja quero o pão: cotidiano e trabalho infantil do menor na citricultura de Boquim/SE (1980-2000). Lagarto, 2002. Monografia (Graduação de Licenciatura em História). Departamento de História, Programa de Qualificação Docente, Universidade Federal de Sergipe.

SANTANA, M. P. C. Políticas sociais e inclusão no Brasil: o programa de erradicação do trabalho infantil (PETI) em Itabaiana/SE, 2000-2005. Aracaju, 2006. Dissertação (Mestrado em Ciências Sociais). Núcleo de Pós-Graduação e Pesquisa em Ciências Sociais, Universidade Federal de Sergipe.

SEIDES. Secretaria de estado da Inclusão, Assistência e Desenvolvimento Social. Disponível em: www.seides.se.gov.br. Acessado em 2009.

UOL NOTÍCIAS. Trabalho infantil no Brasil cai pouco e ainda há 1,2 milhão de crianças vítimas de exploração. Entrevista com Renato Mendes em 18/07/2008, disponível no site: www.uol.com.br. Acessado em23 de agosto de2009.

VASCONCELOS, C. A. 0 uso do território pela citricultura e a permanência do trabalho infantil no centro-sul de Sergipe. São Cristóvão, 2009. Tese (Doutorado em Geografia). Núcleo de Pós-Graduação em Geografia, Universidade Federal de Sergipe.

Recebido em 10.11.2013

Aprovado em 02.12.2013 